\title{
Direct assessment of synovial blood flow and its relation to induced hydrostatic pressure changes
}

\author{
P GEBOREK, K FORSLIND, AND F A WOLLHEIM \\ From the Department of Rheumatology, University Hospital of Lund, Sweden
}

SUMmaRY A method for measuring synovial blood flow changes using the laser Doppler technique is described. Mean blood flow and mean pulse amplitude decreased by $50-70 \%$ in relation to the reference level when the intra-articular hydrostatic pressure in effusive knee joints of patients with rheumatoid arthritis was increased. As an increase of intra-articular pressure of as little as $20 \mathrm{mmHg}$ decreased synovial blood flow significantly it is suggested that hypoxia may occur in vivo during joint use in the presence of an effusion. This may be of aetiopathogenetic importance for tissue destruction and the persistence of chronic synovitis.

Key words: rheumatoid arthritis, laser Doppler technique.

Increased hydrostatic pressure may impair synovial microcirculation. ${ }^{1-4}$ Development of intermittent ischaemia could lead to the formation of oxygen free radicals with subsequent tissue damage. ${ }^{56}$

Synovial blood circulation has been evaluated indirectly by measuring skin temperature, from the synovial fluid temperature, by plethysmography, electromagnetic and bubble flow methods, vital microscopy as well as by clearance of radioactive substances-for example, ${ }^{24} \mathrm{Na},{ }^{131} \mathrm{I},{ }^{123} \mathrm{I},{ }^{7}$ and ${ }^{133} \mathrm{Xe}$, from the synovial fluid. The subject has been reviewed. ${ }^{8-11}$ Evidence of increased blood circulation $^{12-14}$ as well as insufficient nutritional supply ${ }^{3}>13-18$ has been reported in various joint diseases, mostly rheumatoid arthritis. There are also reports of a physiological diffusion block between the synovial capillaries and the synovial fluid in knee joints of patients with rheumatoid arthritis. ${ }^{10} 19$

The described techniques, apart from their indirect approach, all have disadvantages-for example, sensitivity to environmental temperature, lipophilic property of $\mathrm{Xe}^{20}$ introduction of radioactive substances, complicated measuring procedures, and the importance of taking the synovial fluid volume into account in clearance studies. ${ }^{10}$ Furthermore, they are not suited for measuring rapid changes in synovial microcirculation.

Thus a method for measuring rapid microcircula-

Accepted for publication 24 August 1988.

Correspondence to Dr P Geborek, Department of Rheumatology, University Hospital of Lund, S-221 85 Lund, Sweden. tory changes would be a useful tool in the investigation of synovial blood circulation physiology. We introduce the use of a new needle probe permitting synovial microcirculatory measurements with the aid of the laser Doppler technique. The latter has mainly been used to measure skin blood flow. ${ }^{21-23}$ The equipment is suitable for evaluation of rapid changes in synovial blood flow. The purpose of this study was to investigate the impact of intra-articular hydrostatic pressure variations on synovial blood flow.

\section{Materials and methods}

Eight knee joints with effusions in seven patients with classical rheumatoid arthritis ${ }^{24}$ were studied. In one patient both knees were investigated on different occasions. Table 1 gives details of patient characteristics.

A Teflon cannula was introduced into the suprapatellar recess after subcutaneous infiltration of a local anaesthetic. Care was taken not to inject any anaesthetic into the joint cavity. After aspiration of a few millilitres of synovial fluid a laser needle probe connected to a PF2-B laser Doppler instrument (Perimed, Stockholm, Sweden) was inserted through and fixed to the Teflon cannula, which was then directed against the synovial membrane. After obtaining a regular pulse wave registration the cannula was fixed to the skin. As the inner diameter of the cannula exceeded the laser probe by $0.1 \mathrm{~mm}$ measurement of intra-articular hydrostatic pressure 
Table 1 Patient characteristics

\begin{tabular}{|c|c|c|c|c|c|c|}
\hline $\begin{array}{l}\text { Patient } \\
\text { No }\end{array}$ & Sex & $\begin{array}{l}\text { Age } \\
\text { (years) }\end{array}$ & $\begin{array}{l}\text { Duration } \\
\text { of disease } \\
\text { (years) }\end{array}$ & $\begin{array}{l}\text { Total duration } \\
\text { of local disease } \\
\text { (years) }\end{array}$ & $\begin{array}{l}\text { Duration of } \\
\text { synovitis } \\
\text { (months) }\end{array}$ & $\begin{array}{l}\text { Time since } \\
\text { last gluco- } \\
\text { corticosteroid } \\
\text { injection } \\
\text { (months) }\end{array}$ \\
\hline
\end{tabular}

\begin{tabular}{|c|c|c|c|c|c|c|}
\hline 1 & $\mathbf{M}$ & 62 & 10 & 8 & 2 & 3 \\
\hline 2 & $\mathbf{M}$ & 52 & 10 & 5 & 6 & 0.5 \\
\hline 3 & $\mathbf{M}$ & 51 & 5 & 4 & 1 & 6 \\
\hline 4 & $\mathbf{M}$ & 73 & 27 & 20 & 1 & $>12$ \\
\hline 5 & $\mathbf{F}$ & 60 & 12 & 10 & 0.5 & 3 \\
\hline 6 (left) & $\mathbf{F}$ & 60 & 17 & 15 & 0.2 & 2 \\
\hline 6 (right) & & & & 14 & 1 & 2 \\
\hline 7 & $\mathbf{F}$ & 52 & 30 & 21 & 2 & 6 \\
\hline 8 & $\mathbf{F}$ & 49 & 9 & 9 & 1 & 4 \\
\hline
\end{tabular}

could be performed through a side entrance of the cannula. Intra-articular pressure was measured with a hydrostatic pressure transducer (Hewlett-Packard) connected to the cannula side entrance by pressure stiff tubes filled with saline. A $12 \mathrm{~cm}$ wide blood pressure cuff was applied around the knee over the patella, thus exerting the maximal pressure distally to the synovial site studied. The cuff was then inflated with increasing pressures, usually $25-50-75-$ $100-150 \mathrm{mmHg}$. Intra-articular pressure and synovial microcirculation blood flow were registered on a Servogor 2 pen recorder (BBC, Vienna, Austria). Minor adjustments of the needle probe localisation were sometimes necessary owing to movements of the tissues when the external cuff was inflated.

Owing to large variations in resting blood flow a standardisation procedure was performed. The mean blood flow at the external cuff pressure of 0 $\mathrm{mmHg}$ was assigned the reference level $100 \%$. The mean blood flow for each externally applied pressure was standardised according to this reference level. Similarly, mean pulse amplitude at external cuff pressure $0 \mathrm{mmHg}$ was assigned the value $100 \%$ and the mean pulse amplitude for each applied pressure was standardised accordingly. In each registration the atmospheric pressure was assigned the level of $0 \mathrm{mmHg}$ and a standardised hydrostatic pressure recording was included. To evaluate the impact of changes in intra-articular pressure upon synovial blood flow the measured intra-articular hydrostatic pressure at external cuff pressure 0 was subtracted from the subsequently measured pressure.

To validate the blood flow registrations the procedure was performed twice in two knees and three times in one knee joint. For each of the externally applied pressures correlation of the blood flow, pulse amplitude, and intra-articular hydrostatic pressure was performed.
In an attempt to evaluate the possibility that external cuff pressure influenced tissue blood flow proximal to the cuff, cutaneous blood flow was measured over the suprapatellar bursa in two additional arthritic knee joints with effusions. The $\overrightarrow{0}$ cuff around the knee was inflated stepwise to suprasystolic levels two or three times. The distance from the cuff border to the site studied was 8-12 $\mathrm{mm}$, corresponding approximately to the distance of the intra-articular registrations.

The laser Doppler technique also measures cellu lar movements in the tissue not related to bloof circulation. ${ }^{23}$ To evaluate this component an $18 \mathrm{~cm}$ wide blood pressure cuff was applied around the thigh proximal to the cannula and inflated to supra systolic pressures in two cases.

Only experiments in which registrations with regular pulse waves were obtained and in which synovial fluid could be withdrawn after removal of the laser probe were considered to have measured synovial membrane microcirculation (see 'Results' and 'Discussion'). No artefact filter was used. Theo band width was set to $12 \mathrm{kHz}$ and the time constan? was 0.2 seconds to permit registration of rapio changes and also identification of artefacts.

\section{STA T ISTICS}

Spearman's correlation coefficient was used.

\section{Results}

Regular pulse registrations were obtained in alf knees investigated. Synovial fluid was withdrawn after removal of the laser probe from seven of eigh 5

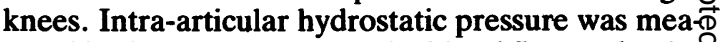
sured in six of these knees. The blood flow and pulse $e_{\mathbb{P}}$ amplitude at the external cuff pressure of $0 \mathrm{mmHg}$ varied markedly beween different knee joints. Afterk standardisation (see 'Materials and methods') 
homogeneous pattern was found when intraarticular hydrostatic pressure was increased, characterised by a progressive decrease in both blood flow and pulse amplitude. Figure $1 \mathrm{~A}$ shows a representative experiment. The mean blood flow decreased to approximately $30 \%$ of the reference level when the increase in intra-articular hydrostatic pressure was above $50 \mathrm{mmHg}$ (Fig. 2). The pulse amplitude showed a similar but more variable decrease (Fig.3). The knee joint in which the hydrostatic pressure was not recorded showed the same changes with increasing external cuff pressure.
Standardised mean blood flow correlated with standardised mean pulse amplitude $(r=0 \cdot 80$, $\mathrm{p}<0.002$; Fig. 4) as well as with the increase in intraarticular hydrostatic pressure $(r=-0.69, p<0.002)$. The correlation between increase in intra-articular hydrostatic pressure and standardised pulse amplitude was $\mathrm{r}=-0.74, \mathrm{p}<0.002$.

Repeat experiments in three individual knee joints in which intra-articular hydrostatic pressures attained with externally applied pressure were measured showed a high reproducibility $(r=0.95$, $\mathrm{p}<0.002$ ). Similarly, registered mean blood flow

A

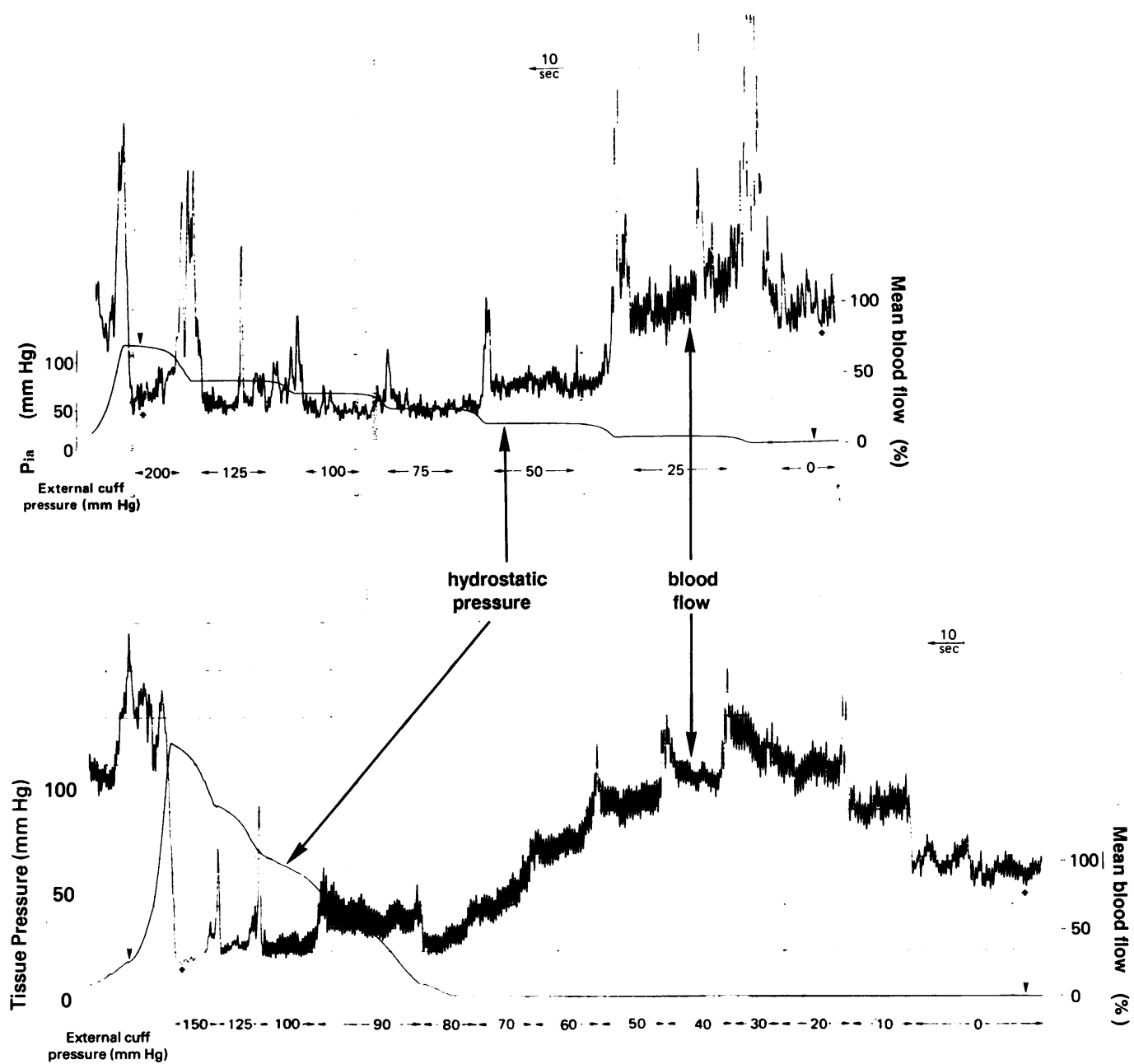

Fig. 1 (A) Registration of intra-articular hydrostatic pressure $\left(P_{i a}\right)$ and synovial blood flow at different external cuff pressures when the cannula was situated in the knee joint cavity. $(B)$ The same registration as in $(A)$, but the cannula probably situated in the joint capsule. Notice that the registrations run from right to left. The large irregular amplitudes of the blood flow recordings represent artefacts due to movements of the laser needle probe. 
and mean pulse amplitude correlated for each externally applied pressure $(r=0.57, p<0.002$ and $\mathrm{r}=0.74, \mathrm{p}<0.002$ respectively). Repeated registrations of cutaneous blood flow remained unchanged when distal cuff pressure was altered.

A residual output signal from the laser Doppler instrument of $9 \%$ and $18 \%$ of the reference level was found in the two cases where the blood flow to the knee had been abrogated by application of suprasystolic pressures around the thigh.

In one experiment no synovial fluid could be withdrawn from the knee joint after removal of the

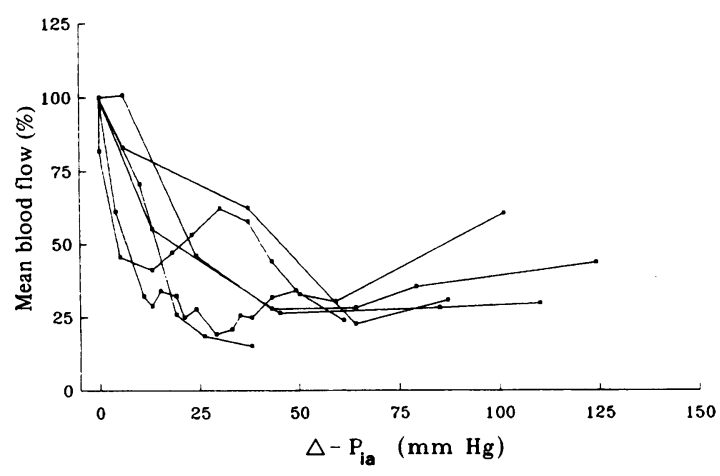

Fig. 2 Changes in mean synovial blood flow versus increases in intra-articular hydrostatic pressure $\left(\Delta-P_{i a}\right)$ in six different knee joints. The increases in intra-articular pressure were obtained by inflating an externally applied cuff. The mean blood flow at external cuff pressure $=0 \mathrm{mmHg}$ was assigned the value $100 \%$.

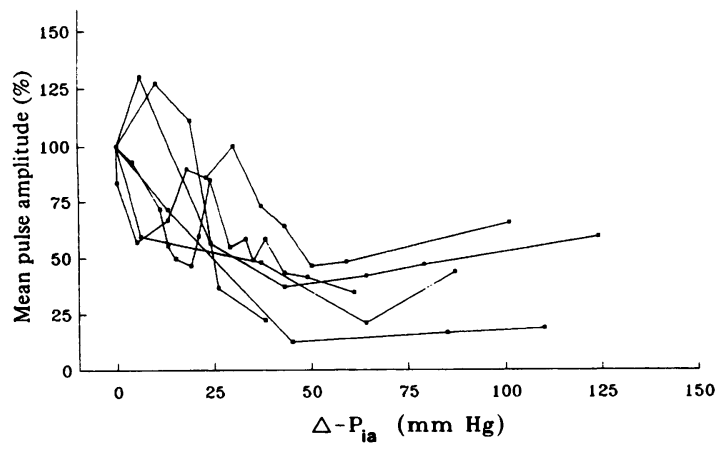

Fig. 3 Changes in mean pulse amplitude versus increases in intra-articular hydrostatic pressure $\left(\triangle-P_{i a}\right)$ in six different knee joints. The increases in intra-articular pressure were obtained by inflating an externally applied cuff. The mean pulse amplitude at external cuff pressure $=0 \mathrm{mmHg}$ was assigned the value $100 \%$.

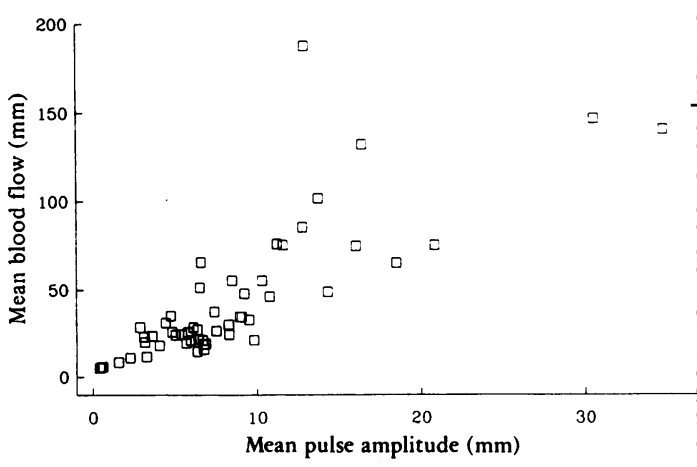

Fig. 4 Mean synovial pulse amplitude versus mean synovial blood flow for each applied cuff pressure. The measurements are the actually recorded deflections in $\mathrm{mm}-$ that is, without the standardisation procedure.

laser probe, and the recorded changes differed as seen in Fig. 1B. In contrast with the usual stepwiseo increments in hydrostatic pressure, the recorded pressure reacted only for cuff pressures above $7 \dot{0}$ $\mathrm{mmHg}$, and then rose progressively. Blood flow and pulse amplitude also showed an atypical pattern which could be reproduced when the procedure was repeated.

The increase of intra-articular pressure for the individual knee joints varied when the same externa $\overrightarrow{\bar{D}}$ pressure was applied to them. Intra-articular hydro static pressure at external cuff pressure $=0 \mathrm{mmH}$ varied between 0 and $36 \mathrm{mmHg}$, median 3 .

In some recordings a rebound phenomenon witls increased blood flow and pulse amplitude was observed when the external pressure was removed 3 . Artefacts due to movement of the optic fibre cable were readily identified by large amplitude anç irregularly shaped curves.

Pulse synchronous oscillations of intra-articula? pressure were observed as the pressure increased as has been described. ${ }^{2}$

\section{Discussion}

Previous investigations of synovial microcirculations have used indirect techniques not suitable for following rapid changes in blood flow. ${ }^{810}$ The lasef Doppler instrument used in our study seems to be $\stackrel{\oplus}{\oplus}$ suitable device for such measurements. The lasefo beam is reflected against corpuscles in a hemispher $\overline{0}$ of about $1 \mathrm{~mm}^{3}$ in front of the probe. The lase Doppler apparatus measures movements in a directions of these corpuscles-that is, mainlf erythrocytes. ${ }^{21}$ It has been shown that the magni tude of the output signal is linearly proportional $t \&$ 
the product of the number and mean velocity of the corpuscles moving in front of the probe. ${ }^{21}$ Thus the device should be useful for comparative measurements of synovial blood flow between different knee joints.

The probe may exert a certain pressure on the synovial membrane, thereby compressing the capillaries and reducing the blood flow at the measured site. The actual investigative design did not allow standardisation of the pressure exerted by the probe on the synovial membrane. The recorded uniform decrease in blood flow with increasing intra-articular pressure (Fig. 2), however, supports the validity of flow measurements by this method.

Alternative methods could be considered to generate increased intra-articular hydrostatic pressure. A distal externally applied cuff was chosen to minimise tissue movements at the site studied. External manual compression and isometric knee extensor muscle activation were difficult to standardise. Knee joint flexion and infusion of a salt solution yielded large movement induced artefacts, and the injection of a fluid also brought problems of obtaining correct temperature. Cuff inflation as we used it did not alter proximal cutaneous blood flow. This supports the inference that the measured increase in intra-articular hydrostatic pressure was indeed the cause of the decreased synovial blood flow.

The laser Doppler technique also measures movements unrelated to blood flow in the tissues, possibly due to other cellular movements. ${ }^{23}$ This was demonstrated in the experiments in which, despite abrogation of the blood circulation to the knee by a proximal cuff, the recorded output signal failed to drop to zero.

Even when intra-articular pressure was above 100 $\mathrm{mmHg}$ the output signal exceeded that after abrogation of the blood flow, suggesting persistent tissue perfusion with raised intra-articular hydrostatic pressure. It was not possible to immobilise the probe completely in relation to the tissues, and some of the apparently measured pulse and blood flow could be artefacts due to pulse synchronous movements of the probe. It is thus possible that the synovial microcirculation was more reduced at increased intra-articular pressures than was actually recorded. The relatively constant level of output signal despite further increase in intra-articular hydrostatic pressure, in one case even above the systolic blood pressure, supports this possibility.

The laser Doppler method showed a good reproducibility when the procedure was repeated in the same knee joint. The uniform pattern of decreased blood flow in different knees with increasing intraarticular pressure also supports the reproducibility of the method, provided that the intra-articular location of the probe was ascertained by aspiration of synovial fluid after removal of the laser probe. The different pattern observed in the joint in which no synovial fluid could be aspirated after removal of the probe (Fig. 1B) indicated that the cannula had slipped out of the joint cavity.

Blood flow and pulse amplitude were closely correlated, indicating that they may reflect related circulatory events (Fig. 4). Decrease in both mean synovial blood flow and pulse amplitude was thus shown even for relatively small increases in intraarticular hydrostatic pressures $(10-30 \mathrm{mmHg})$. Pressures well above these have been measured during joint movement and knee extensor muscle activation in the presence of excess synovial fluid. ${ }^{125-29}$ Even small and intermittent impairments of synovial microcirculation may cause significant joint hypoxia as synovial fluid is often acidotic in rheumatoid arthritis ${ }^{14-18}$ and also lacks significant buffering capacity for oxygen..$^{30}$ Joint hypoxia may be of aetiopathogenetic importance in chronic arthritic diseases. 56

The present investigation showed that synovial microcirculation is reduced by moderate increases in hydrostatic pressures, probably occurring in vivo in effusive joint diseases. The possibility of using the laser Doppler device for comparative measurements of synovial microcirculation in different knee joints is presently being explored.

This investigation was supported by grants from Alfred Österlund Foundation, Greta och Johan Kocks foundation, and the University of Lund. We are grateful to Professor Gert E Nilsson for revising the manuscript and to Lotta Larsson for technical assistance.

\section{References}

1 Caughey D E, Bywaters E G L. Joint fluid pressure in chronic knee effusions. Ann Rheum Dis 1963; 22: 106-9.

2 Jayson M I V, Dixon A St J. Intra-articular pressure in rheumatoid arthritis of the knee. II. Effect of intra-articular pressure on blood circulation to the synovium. Ann Rheum Dis 1970; 29: 266-8.

3 Treuhauft P S, McCarty D J. Synovial fluid pH, lactate, oxygen and carbon-dioxide partial pressure in various joint diseases. Arthritis Rheum 1971; 14: 475-84.

4 Jayson M I V. Intra-articular pressure. Clin Rheum Dis 1981; 7: $149-66$.

5 Woodruff T, Blake D R, Freeman J, Andrews F J, Salt P, Lunec $J$. Is chronic synovitis an example of reperfusion injury? Ann Rheum Dis 1986; 45: 608-11.

6 Allen R E, Outhwaite J M, Morris C J, Blake D R. Xanthine oxidoreductase is present in human synovium. Ann Rheum Dis 1987; 46: 843-5.

7 Wallis W J, Simkin P A, Nelp W P. Low synovial clearance of iodide provides evidence of hypoperfusion in chronic rheumatoid synovitis. Arthritis Rheum 1985; 28: 1096-104.

8 Liew M, Dick W C. The anatomy and physiology of blood flow in diarthrodal joints. Clin Rheum Dis 1981; 7: 131-48.

9 Kennedy A C. Joint temperature. Clin Rheum Dis 1981; 7: 177-88. 
10 Simkin P A, Nilson K L. Trans-synovial exchange of large and small molecules. Clin Rheum Dis 1981; 7: 99-129.

11 Levick J R. Blood flow and mass transport in synovial joints. In: Renkin E M, Michel C C, eds. Handbook of physiology, the cardiovascular system $I V$, the microcirculation, part 2 . Bethesda: American Physiology Society, 1984.

12 Falchuk K H, Goetzl E J, Kulka J P. Respiratory gases of synovial fluid. An approach to synovial tissue circulatorymetabolic imbalance in rheumatoid arthritis. Am J Med 1970; 49: 223-31.

13 Goetzl E J, Falchuk K H, Zieger L S, et al. A physiological approach to the assessment of disease activity in rheumatoid arthritis. J Clin Invest 1971; 50: 1167-80.

14 Lund-Olesen K. Oxygen tension in synovial fluids. Arthritis Rheum 1970; 13: 769-76.

15 Goetzl E J, Rynes R I, Stillman J S. Abnormalities of respiratory gases in synovial fluid of patients with juvenile rheumatoid arthritis. Arthritis Rheum 1974; 17: 450-4.

16 Niinikoski J, Einola S. Postoperative synovial fluid. Metabolic response to meniscectomy or synovectomy. Acta Orthop Scand 1977; 48: 129-37.

17 Richman A I, Su E Y, Ho G Jr. Reciprocal relationship of synovial fluid volume and oxygen tension. Arthritis Rheum 1981; 24: 701-5.

18 Brothers G B Jr, Hadler N M. Diurnal variations in rheumatoid synovial effusions. J Rheumatol 1983; 10: 471-4.

19 Simkin P A, Pizzorno J E. Synovial permeability in rheumatoid arthritis. Arthritis Rheum 1979; 22: 689-96.

20 Phelps P, Steele A D, McCarty D J. Significance of xenon-133 clearance rate from canine and human joints. Arthritis Rheum 1972; 15: 360-70.
21 Nilsson G E, Tenland T, Öberg $P \AA$. Evaluation of a laser $\frac{}{\mathcal{N}}$ Doppler flowmeter for measurement of tissue blood flow. IEEE Trans Biomed Eng 1980; 27: 597-604.

22 Nilsson G E, Tenland T, Öberg P $\AA$. A new instrument for continuous measurement of tissue blood flow by light beating spectroscopy. IEEE Trans Biomed Eng 1980; 27: 12-19.

23 Tenland T, Salerud E G, Nilsson G E, Öberg P Á. Spatial and temporal variations in human skin blood flow. Int $J$ Microcir $\mathbb{D}$ Clin Exp 1983; 2: 81-90.

24 Ropes M W, Bennett G A, Cobb S, Jacox R, Jessar R A. (ֶ) Diagnostic criteria for rheumatoid arthritis: 1958 revision. $A n n \vec{\circ}$ Rheum Dis 1959; 18: 49-54.

25 deAndrade J R, Grant C, Dixon A St J. Joint distension and reflex muscle inhibition in the knee. J Bone Joint Surg [Am] 1965; 47: 313-22.

26 Palmer D G, Myers D B. Some observations of joint effusions Arthritis Rheum 1968; 11: 745-55.

27 Jayson M I V, Dixon A St J. Intra-articular pressure in ${ }^{+}$ rheumatoid arthritis of the knee. I. Pressure changes duringo passive joint distension. Ann Rheum Dis 1970; 29: 261-5.

28 Jayson M I V, Dixon A St J. Intra-articular pressure in음 rheumatoid arthritis of the knee. III. Pressure changes during joint use. Ann Rheum Dis 1970; 29: 401-8.

29 Myers D B, Palmer D G. Capsular compliance and pressurevolume relationships in normal and arthritic knees. J Bone Join Surg [Br] 1972; 54: 710-6.

30 Geborek P, Lindoff B, Valind S. Measurement of oxygen ande carbon dioxide partial pressures in synovial fluid after tonometry. Clin Physiol 1988; 8: 427-32. 